\title{
Relationships between cognitive emotion regulation strategies with depression and anxiety
}

\author{
Majid Pourfaraj Omran
}

Islamic Azad University, Behshahr Branch, Behshahr, Iran.

Email: m.pourfaraj@gmail.com

Received 20 August 2011; revised 16 September 2011; accepted 10 October 2011.

\begin{abstract}
In current study firstly, psychometric properties of Cognitive Emotion Regulation Questionnaire (CERQ) in an Iranian sample were examined. The result of factor analysis, subscales correlations, internal consistency and test-retest coefficients showed good psychometric properties of CERQ in Iran. Secondly, relationships between cognitive emotion regulation strategies with depression and anxiety were studied by multiple regression analysis. The result showed that catastrophizing, self-blame and rumination were related with high level of anxiety and depression and refocusing, positive reappraisal and planning subscales related with low level of anxiety and depression.
\end{abstract}

Keywords: Cognitive Emotion Regulation; Depression; Anxiety

\section{INTRODUCTION}

Emotion regulation includes a wide range of conscious and unconscious physiological, behavioral, and cognitive strategies that are used to reduce, maintain, or increase an emotion [1]. Cognitive emotion regulation (CER) involves the cognitive way of handling the intake of emotionally arousing information [2,3]. A relatively new scale, the Cognitive Emotion Regulation Questionnaire (CERQ), was developed to assess cognitive coping to stressful life events. This questionnaire includes nine cognitive strategies: self-blame, referring to thoughts of putting the blame of what person has experienced on her/himself; other-blame, referring to thoughts of putting the blame of what person has experienced on the environment or another person; rumination, referring to thinking about the feelings and thoughts associated with the negative event; catastrophizing, referring to thoughts of explicitly emphasizing the terror of what person has experienced; putting into Perspective, referring to downgrading the importance of the event; positive refocusing, referring to thinking about positive experiences instead of thinking about the actual event; positive reappraisal, referring to thoughts of giving the event a positive meaning in terms of personal growth; acceptance, referring to thoughts of resigning person to what has happened and planning, referring to thinking about what steps to take and how to handle the negative event [4].

The CERQ has been included in an increasing number of studies in various countries focusing on relationships between cognitive processes and mental health. Despite some variation across studies, cognitive strategies such as self-blame, rumination, catastrophizing and positive reappraisal (inversely) have consistently been associated with negative emotions like depression, anxiety, stress and anger [4-9].

In this research for obtain more knowledge about cross cultural difference about CER and its role in anxiety and depression, firstly, psychometric properties of CERQ in an Iranian sample was studied and then relationship between CER with anxiety and depression was examined.

\section{METHOD}

\subsection{Subjects}

Four hundred eighty four undergraduate students (265 males) with randomize cluster sampling were selected from various departments of Shiraz University. The age of the samples ranged from 18 to 32 years with a mean of 22.14 $(\mathrm{SD}=4.02)$.

\subsection{Instruments}

\subsubsection{Cognitive Emotion Regulation Questionnaire (CERQ)}

The CERQ was developed in 1999 for measuring the cognitive emotion regulation strategies that subjects use in response to the experience of stressful life events [6]. The CERQ is a self-report questionnaire and has 36 -item and 9 subscales (i.e., self-blame, other-blame, rumination, catastrophizing, putting into perspective, positive refocusing, positive reappraisal, acceptance and planning). Items are 
measured on a 5-point Likert scale ranging from 1 (almost never) to 5 (almost always). The CERQ can be use$\mathrm{d}$ to measure cognitive strategies that characterize the individual's style of responding to stressful events as well as cognitive strategies that are used in a particular stressful event or situation, depending on the nature of the questions under study. In this study was used from questions about stressful events. Individual subscale scores are obtained by summing up the scores belonging to the particular subscale (ranging from 4 to 20). The psychometric properties of the CERQ have been proven to be good $[10,11]$, with Cronbach's alpha coefficients in most cases well over 0.70 and in many cases even over 0.80 . Moreover, the CERQ has been shown to have good factorial validity, discriminative properties and construct validity [6].

\subsubsection{Beck Depression Inventory II (BDI-II)}

The BDI-II, second edition of BDI, is a 21-item measure that is widely used to assess cognitive, affective, somatic, and behavioral symptoms of depression. Scores on the BDI have range from 0 (no symptoms) to 63 (very severe symptoms). The psychometric properties of the scale are supported [12]. In Iran the psychometric properties of a Persian-language version of the this inventory examined with compared mean item scores on the BDIII-Persian with those on the English-language version administered to North American college students [13]. In this study assessed internal consistency and test- retest reliability and its concurrent validity against a measure of negative automatic thoughts in depression, the Automatic Thoughts Questionnaire [14]. They also examined the factor structure of the BDI-II-Persian through comparing the fit of various proposed models to the data using confirmatory factor analysis. The BDI-II-Persian had high internal consistency (Cronbach's alpha $=0.87$ ) and acceptable test-retest reliability $(r=0.74)$. The instrument correlated strongly with the Automatic Thoughts Questionnaire. In factor analysis, models with strongly correlated affective-cognitive and somatic-vegetative factors provided a better fit than models with one global factor.

\subsubsection{State-Trait Anxiety Inventory (STAI)}

The STAI is a 40 -item self-report measure of general anxiety. The first 20 items assess state anxiety, or how the participant feels 'right now;' the second 20 items assess trait anxiety, or how the participant feels 'generally.' The STAI has high reliability and validity [15]. Mahram [16] in his study about standardization STAI in Iran reported this inventory has good psychometric properties in Iran.

\subsection{Procedure}

The instruments were administered during or after regular class hours. Before the administration, instructions about procedure of responding to inventories were given to the participants.

\section{RESULT}

\subsection{Factor Structure}

The factorial structure of the Persian version of the CERQ was investigated with an exploratory principal components (PCA) followed by varimax rotation. Items were included on a factor if the loading was 0.40 or higher. This analysis revealed nine factors with eigenvalues greater than 1 , accounting for $76 \%$ of the total variance. The results of factor analyses were summarized in Table 1.

Table 1. Factor structure of CERQ.

\begin{tabular}{|c|c|}
\hline Factors and items & Loading \\
\hline \multicolumn{2}{|l|}{ Self-blame } \\
\hline I feel that I am the one to blame for it & 0.68 \\
\hline $\begin{array}{l}\text { I feel that I am the one who is responsible for what has } \\
\text { hapnened }\end{array}$ & 0.71 \\
\hline I think about the mistakes I have made in this matter & 0.64 \\
\hline I think that basically the cause must lie within myself & 0.75 \\
\hline \multicolumn{2}{|l|}{ Other-blame } \\
\hline I feel that others are to blame for it & 0.72 \\
\hline I feel that others are responsible for what has happened & 0.64 \\
\hline I think about the mistakes others have made in this matter & 0.59 \\
\hline I feel that basically the cause lies with others & 0.61 \\
\hline \multicolumn{2}{|l|}{ Rumination } \\
\hline $\begin{array}{l}\text { I often think about how I feel about what I have experi- } \\
\text { enced }\end{array}$ & 0.69 \\
\hline $\begin{array}{l}\text { I am preoccupied with what I think and feel about what I } \\
\text { have experienced }\end{array}$ & 0.78 \\
\hline $\begin{array}{l}\text { I want to understand why I feel the way I do about what I } \\
\text { have experienced }\end{array}$ & 0.66 \\
\hline I dwell upon the feelings the situation has evoked in me & 0.63 \\
\hline \multicolumn{2}{|l|}{ Catastrophizing } \\
\hline $\begin{array}{l}\text { I often think that what I have experienced is much worse } \\
\text { than what others have experienced }\end{array}$ & 0.77 \\
\hline $\begin{array}{l}\text { I keep thinking about how terrible it is what I have experi- } \\
\text { enced }\end{array}$ & 0.71 \\
\hline $\begin{array}{l}\text { I often think that what I have experienced is the worst that } \\
\text { can happen to a person }\end{array}$ & 0.72 \\
\hline I continually think how horrible the situation has been & 0.75 \\
\hline \multicolumn{2}{|l|}{ Refocus on planning } \\
\hline I think of what I can do best & 0.69 \\
\hline I think about how I can best cope with the situation & 0.73 \\
\hline I think about how to change the situation & 0.65 \\
\hline I think about a plan of what I can do best & 0.79 \\
\hline \multicolumn{2}{|l|}{ Positive reappraisal } \\
\hline I think I can learn something from the situation & 0.58 \\
\hline $\begin{array}{l}\text { I think that I can become a stronger person as a result of } \\
\text { what has happened }\end{array}$ & 0.66 \\
\hline I think that the situation also has its positive sides & 0.71 \\
\hline I look for the positive sides to the matter & 0.75 \\
\hline \multicolumn{2}{|l|}{ Putting into perspective } \\
\hline I think that it all could have been much worse & 0.56 \\
\hline $\begin{array}{l}\text { I think that other people go through much worse experi- } \\
\text { ences }\end{array}$ & 0.69 \\
\hline I think that it hasn't been too bad compared to other things & 0.71 \\
\hline I tell myself that there are worse things in life & 0.67 \\
\hline \multicolumn{2}{|l|}{ Acceptance } \\
\hline I think that I have to accept that this has happened & 0.70 \\
\hline I think that I have to accept the situation & 0.64 \\
\hline I think that I cannot change anything about it & 0.71 \\
\hline I think that I must learn to live with it & 0.57 \\
\hline \multicolumn{2}{|l|}{ Positive refocusing } \\
\hline I think of nicer things than what I have experienced & 0.70 \\
\hline I think of pleasant things that have nothing to do with it & 0.68 \\
\hline I think of something nice instead of what has happened & 0.59 \\
\hline I think about pleasant experiences & 0.65 \\
\hline
\end{tabular}




\subsection{Reliability}

Internal consistency (Cronbach's alpha), and test-retest coefficients for with 3 weeks interval $(\mathrm{N}=30$; one class of original sample) was computed for each CERQ subscale. The result was shown in Table 2.

\subsection{Subscales Correlations}

Correlations between subscales were summarized in Table 3. The correlation matrix shows that the correlations among subscales that are conceptually inverse (e.g. Self-blame vs. other-blame, catastrophizing vs. positive reappraisal and putting into perspective) are significantly negative but subscales that are conceptually near (e.g. putting into perspective, positive refocusing, positive reappraisal and acceptance) are significantly positive.

\subsection{Relationships between CER with Depression and Anxiety}

For investigation relationships between CER with depression and anxiety was used from BDI-II and STAI. The result of multiple regression analyses (Table 4) that were performed with depression and anxiety scales as dependent variables and the CERQ as independent variables shows both regression models were significant $(\mathrm{p}<$ 0.001 ) and explained 0.42 and 0.45 percentage for the prediction of depression and anxiety, respectively. Catastrophizing, self-blame and rumination subscales were strongest predictors of anxiety and depression and related with high level of anxiety and depression, but refocusing, positive reappraisal and planning subscales related with low level of anxiety and depression.

Table 2. Means, standard deviations and reliability of CERQ.

\begin{tabular}{cccc}
\hline Subscales & Mean (SD) & $\alpha$ & Test-retest \\
\hline Self-blame & $10.44(3.52)$ & 0.69 & 0.61 \\
Other-blame & $7.64(1.65)$ & 0.77 & 0.66 \\
Rumination & $11.21(4.02)$ & 0.76 & 0.59 \\
Catastrophizing & $8.09(2.45)$ & 0.68 & 0.60 \\
Planning & $10.61(3.63)$ & 0.80 & 0.65 \\
Positive reappraisal & $9.89(3.95)$ & 0.75 & 0.57 \\
Putting into perspective & $10.96(2.98)$ & 0.70 & 0.69 \\
Acceptance & $8.65(3.31)$ & 0.72 & 0.66 \\
Positive refocusing & $9.55(3.01)$ & 0.79 & 0.62 \\
\hline
\end{tabular}

Table 3. Correlations between CERQ subscales.

\begin{tabular}{|c|c|c|c|c|c|c|c|c|}
\hline 8 & 7 & 6 & 5 & 4 & 3 & 2 & 1 & CERQ subscales \\
\hline & & & & & & & & 1. Self-blame \\
\hline & & & & & & & $0.21 * *$ & 2. Acceptance \\
\hline & & & & & & $0.27 * * *$ & $0.17 * *$ & 3. Rumination \\
\hline & & & & & 0.05 & $0.24 * * *$ & 0.08 & 4. Positive refocusing \\
\hline & & & & $0.18^{* *}$ & $0.33 * * *$ & $0.28 * * *$ & $0.40 * * *$ & 5. Planning \\
\hline & & $0.41 * * *$ & $0.38 * * *$ & $0.36^{* * *}$ & 0.06 & $0.27 * * *$ & $0.18^{* *}$ & 7. Putting into perspective \\
\hline & $-0.13 *$ & $-0.11^{*}$ & 0.03 & -0.07 & $0.46 * * *$ & 0.05 & $0.20 * *$ & 8. Catastrophizing \\
\hline $0.36 * * *$ & 0.03 & -0.02 & 0.05 & 0.03 & $0.25 * * *$ & -0.02 & $-0.13 *$ & 9. Other-blame \\
\hline
\end{tabular}

$* \mathrm{p}<0.05 ; * * \mathrm{p}<0.01 ; * * * \mathrm{p}<0.001$.

Table 4. Relationships between CER strategies with depression and anxiety (multiple regression analysis)'.

\begin{tabular}{lll}
\hline Subscales & BDI-II(Beta) & STAI(Beta) \\
\hline 1. Self-blame & $0.26^{* * *}$ & $0.20^{* *}$ \\
2. Acceptance & 0.04 & 0.01 \\
3. Rumination & $0.23^{* * *}$ & $0.31^{* * *}$ \\
4. Positive refocusing & $-0.26^{* * *}$ & $-0.24^{* * *}$ \\
5. Planning & $-0.16^{* *}$ & $-0.11^{*}$ \\
6. Positive reappraisal & -0.06 & -0.08 \\
7. Putting into perspective & $-0.12^{*}$ & $-0.15^{* *}$ \\
8.Catastrophizing & $0.32^{* * *}$ & $0.41^{* * *}$ \\
9. Other-blame & 0.06 & 0.02 \\
$R^{2}$ & $0.42^{* * *}$ & $0.45^{* * *}$ \\
\hline
\end{tabular}

BDI-II = Beck Depression Inventory II; STAI = State-trait Anxiety Inventory; ${ }^{*} \mathrm{p}<0.05 ; * * \mathrm{p}<0.01 ; * * * \mathrm{p}<0.001$.

\section{DISCUSSION}

The aim of this study was determination psychometric properties of the CERQ in Iran and relationship between CER with anxiety and depression. For study of validity factor analysis, criterion validity and subscales correlations were used. Factor analysis of CERQ yielded nine factors that are labeled as: self-blame, other-blame, rumination, catastrophizing, putting into perspective, positive refocusing, positive reappraisal, acceptance and planning. Low to moderate negative correlations among subscales that are conceptually in versus with together and positive correlations among subscales that are conceptually near together could show fit construct validity of this questionnaire.

The result of internal consistency (Cronbach's alpha) and 
test-retest coefficients shows good reliability of CERQ. Totally, these results are comparable with result of Garnefski and Kraaij [4]. Accordingly, this study showed that CERQ has fit psychometric properties and could be used for clinical and investigative purposes in Iran.

The result of multiple regression analysis about relationship between CER strategies with depression and anxiety showed that CER strategies explained relatively high amount variances of depression and anxiety. Catastrophizing, self-blame and rumination subscales were related with high level of anxiety and depression, also refocusing, positive reappraisal and planning subscales related with low level of anxiety and depression. This result is similar to the result of Garnefski and Kraaij [4].

The results suggest that self-blame is related to the reporting of symptoms of depression and anxiety. This finding confirms other studies showing that an attributional style of putting the blame of what you have experienced on yourself is related to depression and other measures of ill-health [17].

The results also showed a strong impact style of rumination in symptoms of depression and anxiety, fitting in with the results of Nolen-Hoeksema et al. [18] who showed that a ruminative coping style tended to be associated with higher levels of depression. The present study adds that rumination is also an important predictor of symptoms of depression and anxiety.

In this article for study relationship between CER strategies with depression and anxiety was used from normal group. For future similar study in this field is suggested using from clinical groups for reach to more firm evident about relationship between CER and psychopathology.

\section{REFERENCES}

[1] Gross, J.J. (2001) Emotion regulation in adulthood: Timing is everything. Current Directions in Psychological Science, 10, 214-219. doi:10.1111/1467-8721.00152

[2] Thompson, R.A. (1991) Emotional regulation and emotional development. Educational Psychology Review, 3, 269-307. doi:10.1007/BF01319934

[3] Ochsner, K.N. and Gross, J.J. (2005) The cognitive control of emotion. Trends in Cognitive Sciences, 9, 242249. doi:10.1016/j.tics.2005.03.010

[4] Garnefski, N. and Kraaij, V. (2006) Cognitive emotion regulation questionnaire-development of a short 18item version (CERQ-short). Personality and Individual Differences, 41, 1045-1053. doi:10.1016/j.paid.2006.04.010

[5] Garnefski, N., Kraaij, V. and Spinhoven, Ph. (2001) Negative life events, cognitive emotion regulation and de- pression. Personality and Individual Differences, 30 , 1311-1327. doi:10.1016/S0191-8869(00)00113-6

[6] Garnefski, N., van den Kommer, T., Kraaij, V., Teerds, J., Legerstee, J. and Onstein, E. (2002) The relationship between cognitive emotion regulation strategies and emotional problems. European Journal of Personality, 16, 403420. doi:10.1002/per.458

[7] Garnefski, N., Kraaij, V. and Spinhoven, Ph. (2002) Manual for the use of the cognitive emotion regulation questionnaire. The Netherlands: DATEC, Leiderdorp.

[8] Jermann, F., van der Linden, M., d'Acremont, M. and Zermatten, A. (2006). Cognitive Emotion Regulation (CERQ): Confirmatory factor analysis and psychometric properties of the French translation. European Journal of Psychological Assessment, 22, 126-131. doi: 10.1027/1015-5759.22.2.126

[9] Martin, R.C. and Dahlen, E.R. (2005) Cognitive emotion regulation in the prediction of depression, anxiety, stress and anger. Personality and Individual Differences, 39, 1249-1260. doi:10.1016/j.paid.2005.06.004

[10] D'Acremont, M. and van der Linden, M. (2006) How is impulsivity related to depression? Evidence from a French validation of the cognitive emotion regulation questionnaire. Journal of Adolescence, 24, 65-75.

[11] Kraaij, V., Garnefski, N. and van Gerwen, L. (2003) Cognitive coping and anxiety symptoms among people who seek help for fear of flying. Aviation, Space and Environmental Medicine, 74, 273-277.

[12] Beck, A.T., Steer, R.A. and Brown, G.K. (1996). Manual for the beck depression inventory-II. Harcourt Brace \& Company San Antonio, the Psychological Corporation.

[13] Ghassemzadeh, H., Mojtabai, R. Karamghadiri, N. and Ebrahimkhani, N. (2005) Psychometric properties of a Persian-language version of the beck depression inventory-second edition: BDI-II-PERSIAN. Depression and Anxiety, 21, 185-192.

[14] Hollon, S.D. and Kendall, P.C. (1980) Cognitive selfstatements in depression: Development of an automatic thoughts questionnaire. Cognitive Therapy and Research, 4, 383-395. doi:10.1007/BF01178214

[15] Speilberger, C.D., Gorsuch, R.L., Lushene, R., Vagg, P.R. and Jacobs, G.A. (1983) Manual for the state-trait anxiety inventory. Consulting Psychologists Press, Palo Alto.

[16] Mahram, B. (1993) Standardization speilberger state-trait anxiety inventory in Mashad city (Iran). MA thesis of Ferdousi University, Mashad.

[17] Anderson, C.A., Miller, R.S., Riger, A.L., Dill, J.C. and Sedikides, C. (1994) Behavioural and characterological styles as predictors of depression and loneliness: Review, refinement, and test. Journal of Personality and Social Psychology, 66, 549-558. doi:10.1037/0022-3514.66.3.549

[18] Nolen-Hoeksema, S., Parker, L.E. and Larson, J. (1994) Ruminative coping with depressed mood following loss. Journal of Personality and Social Psychology, 67, 92104. doi:10.1037/0022-3514.67.1.92 